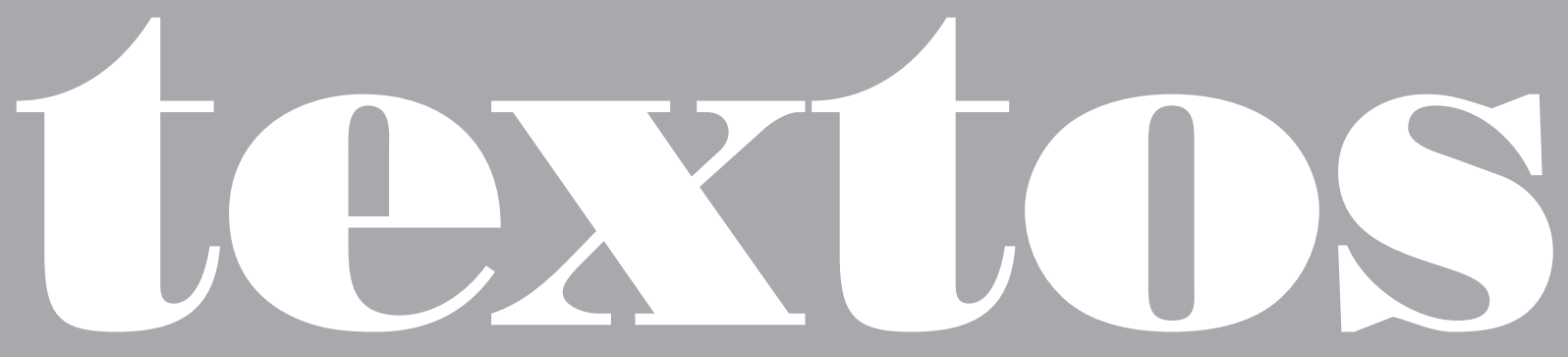





\title{
Marx, as classes sociais e o enigma do capítulo 52
}

\author{
José Nun
}

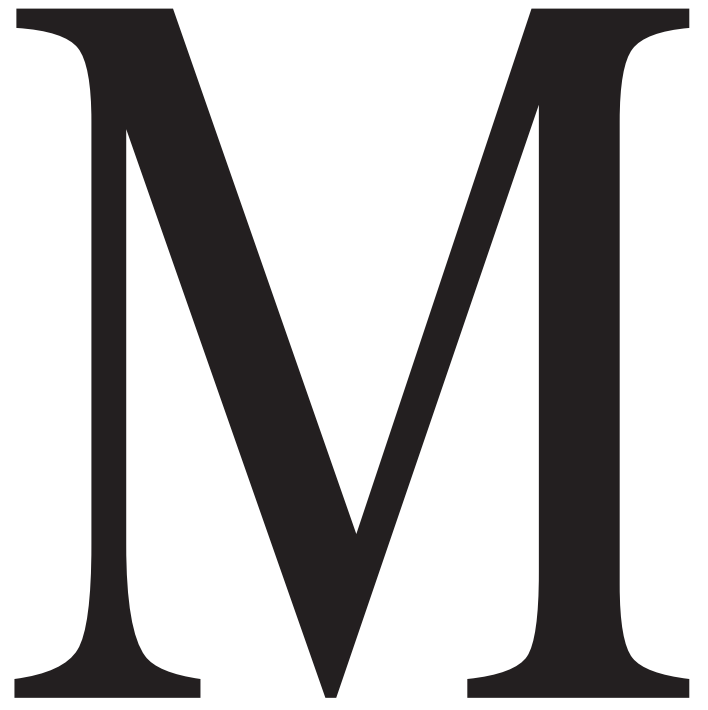

Outra versão deste texto encerra o volume coordenado por Mariana Heredia, Maristella Svampa e Sebastián Pereyra, José Nun y las ciencias sociales. Aportes que perduran (Buenos Aires, Editorial Biblos, 2019).

1 Ver, por exemplo, a Pesquisa Mundial da BBC News Online (1\%/10/1999) e Hart (2000).

JOSÉ NUM é advogado, escritor, ensaísta e ex-ministro da Cultura da Argentina (2004-2009). 
ainda, por que durante seus últimos 15 anos de vida permaneceram intocados os rascunhos dos volumes II e III dessa obra, que Engels publicaria postumamente (cf. Wolff , 2018). A isso soma-se que durante esse período não escreveu nem completou nenhum trabalho importante, entregue à atividade política (em 1864 fundou a Primeira Internacional), e, vítima da pobreza, de enfermidade e de uma "depressão mental crônica", apesar de tudo continuou lendo muito e inclusive começou a aprender russo.

O que aconteceu? Minha hipótese é que, precisamente ao começar a escrever o capítulo sobre as classes sociais, percebeu que não poderia ignorar a existência de um problema que questionava uma parte central de sua estrutura teórica e que não conseguiu resolver porque, tal como estava apresentado, não tinha solução ${ }^{2}$. Adianto muito superficialmente a narrativa na qual tentarei apoiar meu argumento.

Como assinalei anos atrás, em suas análises do modo de produção capitalista, Marx distinguia dois tipos de contradições ${ }^{3}$. Um é o que entende como antagonistas os proprietários dos meios de produção e os trabalhadores assalariados. Longe de ser um obstáculo para o crescimento, essa

2 Apesar de partir de uma perspectiva muito diferente da minha e se referindo a $O$ capital em seu conjunto, José Aricó afirma que "as razões para que a obra ficasse inconclusa, mais que a uma saúde deteriorada, se devem a problemas teóricos que o autor não chegou a resolver" (Aricó, 1971 p. IX).

3 Retomo quase literalmente uma passagem de meu artigo "Superpoblación relativa, ejército industrial de reserva y masa marginal" (Revista Latinoamericana de Sociología, vol. V, n. 2, 1969, pp. 178-236), reproduzido em: Nun (2001, p. 105). contradição impulsiona-o vigorosamente e permite-lhe liquidar as formas produtivas anteriores. O segundo tipo só surge, por sua vez, quando o regime alcançou sua plena maturidade, momento em que as forças produtivas entram em contradição com as relações de produção vigentes, que distorcem ou impedem seu subsequente desenvolvimento. Essa é a contradição fundamental, que não pode ser superada sem uma transformação revolucionária do sistema e que constitui o limite interno de sua evolução possível. À diferença da primeira, não é intencional, "aparece sem que ninguém tenha querido fazê-la aparecer" e expressa "as propriedades objetivas do modo de produção capitalista - quer dizer, não dos capitalistas enquanto indivíduos ou agentes econômicos, nem tampouco dos operários" (Godelier, 1966, p. 79).

É aqui que se apresenta o problema ao qual me refiro, uma vez que ambos os tipos de contradição acabam sendo inconciliáveis entre si. Explico-me.

\section{2.}

Para começar, até há uns 60 anos, quando foram conhecidos os Grundris$s e$, isto é, os volumosos rascunhos de $O$ capital, ignorava-se - nada mais e nada menos - como concretamente Marx supunha que algum dia o capitalismo seria derrubado, abrindo, assim, o caminho para a revolução social que anunciava ${ }^{4}$.

4 A rigor, foi publicada uma edição russa de Grundrisse em 1939/41, mas, na verdade, a obra permaneceu ignorada até 1953, quando apareceu em Berlim uma versão alemã. 
Até então, seus seguidores e seus críticos se contentavam com fórmulas tão gerais como a que supõe que nenhum modo de produção desaparece antes de ter esgotado todas as suas possibilidades de desenvolvimento, momento em que se inicia um período revolucionário ${ }^{5}$.

Por exemplo, em uma obra muito difundida de 1942, Sweezy - que não conheceu os Grundrisse - não duvida de que, alcançado esse ponto, "a classe trabalhadora oprimida e disciplinada por sua posição especial na sociedade derrubará as relações de produção existentes e estabelecerá em seu lugar relações de produção superiores". E acrescenta que, "de acordo com Marx, esse não é um processo que pode ocorrer, mas que deve ocorrer com toda a força inevitável de uma lei natural" (Sweezy, 1945, p. 211). Ou, para dizê-lo nos termos de Marx de 1845, “o proletariado é chamado a executar a sentença que a propriedade privada pronuncia sobre si mesma ao engendrar o proletariado" (apud Shenk, 2017, p. 17).

É precisamente nos Grundrisse - que foram qualificados com razão como "uma obra-prima sem polimento" que contém "o elo perdido entre o Marx maduro e o Marx jovem" (Nicolaus, 1971) ${ }^{6}$ - que o tema recebe sua maior elaboração, com as significativas consequências que logo comentarei e que sustentam minha hipótese.

5 Contorno, por seu caráter conciso e demasiado geral, as notas que Marx escreveu em 1875 e que foram publicadas postumamente com o título de Crítica ao Programa de Gotha.

6 A seguir, no texto, vou me referir a essa obra de Marx como os Grundrisse.
3.

Já no início do século XVII, Francis Bacon havia criticado fortemente Aristóteles por sua negação da ciência aplicada e atribuído o atraso medieval à grande influência que as doutrinas do Estagirita exerceram desde o século XII. Pelo contrário, o filósofo inglês defendia uma fusão entre a ciência e a técnica e recomendava aos cientistas que aprendessem com os artesãos e, aos artesãos, que se interessassem pelos descobrimentos dos cientistas. A partir de então, durante os séculos XVII e XVIII cresceu na Europa a paixão pelo desenvolvimento tecnológico e prosperaram também as mais variadas e audazes especulações em torno dos processos de automatização. O que naquela época não foi visto com bons olhos por autores como Thomas Carlyle ou Alexis de Tocqueville chamou a atenção de Marx.

Por esse motivo foi dito com razão que O Manifesto Comunista (1848) é, em boa medida, um canto à burguesia que, "mediante o rápido aperfeiçoamento de todos os instrumentos de produção e o constante progresso de comunicações cada vez mais fáceis, arrasta à civilização todas as nações, incluindo as mais bárbaras”. Mais ainda, graças à sua "revolução permanente da produção", a burguesia "trouxe à luz o que a atividade humana pode conseguir" e criou, assim, "obras maravilhosas".

Pois bem. Apesar de nos Grundrisse o marco explicativo ser radicalmente modificado (por exemplo, em 1848 o pensamento de Marx se inspirava ainda em Ricardo e girava em torno do mercado, sem vislumbrar as teorias do valor e da mais-valia que seus rascunhos formula- 
riam detalhadamente), a ênfase no papel central que o progresso tecnológico exerce no capitalismo se mantém com tanta ou maior força. De fato, vira-se a chave para decifrar o enigma de sua concepção da derrocada do capitalismo.

Seu argumento é diáfano: à medida que se desenvolvem as forças de produção capitalistas, a produtividade da "grande indústria" depende cada vez mais do "estado geral da ciência e do progresso da tecnologia ou da aplicação dessa ciência na produção". Se em um primeiro momento as inovações resultam principalmente do talento de inventores individuais, a capacidade de gerá-las logo se tornará função do processo de produção, dando mesmo lugar a uma automatização crescente. Quer dizer que as máquinas substituirão o trabalhador e que somente serão necessários para operá-las uns poucos trabalhadores que atuem basicamente como supervisores e reguladores. $\mathrm{Ou}$ seja, que "a criação da riqueza efetiva" se tornará independente "do tempo de trabalho e da quantidade de trabalho empregada" e dessa maneira "desabará a produção baseada no valor de troca"?.

Daí que o capital seja uma contradição em curso:

"Por um lado, desperta para a vida todos os poderes da ciência e da natureza, bem como da cooperação e do intercâmbio sociais, para fazer com que a criação da riqueza seja (relativamente) independente do tempo de trabalho empregado nela.

7 Todas as citações desta seção remetem a Marx (1972, pp. 227-37)

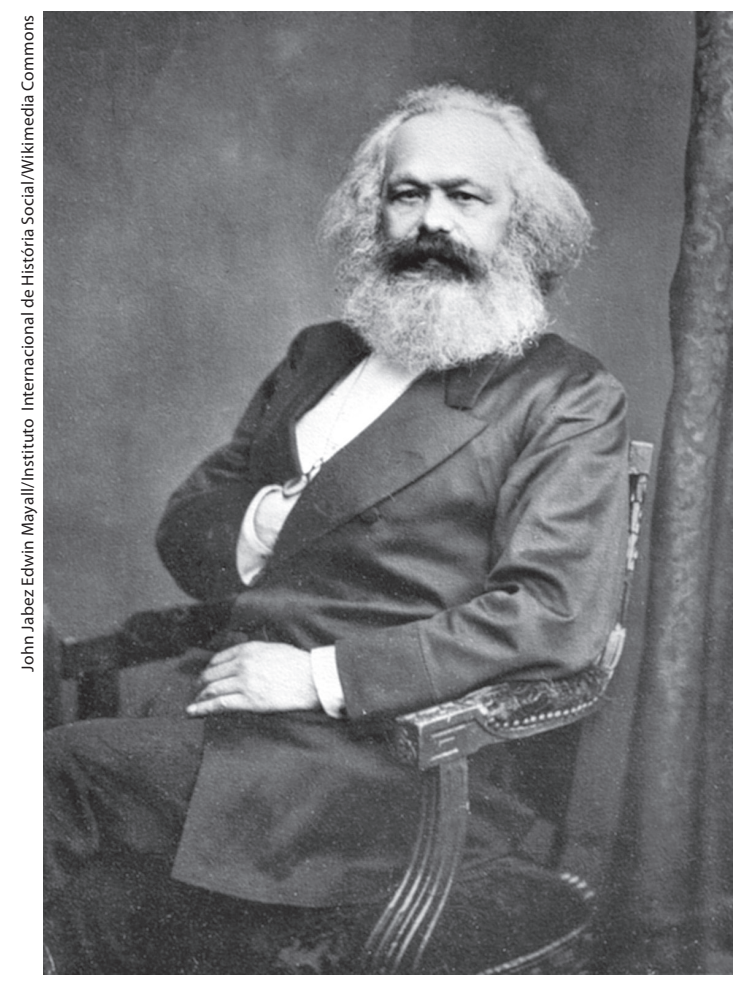

Retrato de Karl Marx

Por outro lado, propõe-se a medir com o tempo de trabalho as gigantescas forças sociais criadas dessa maneira e reduzi-las aos limites exigidos para que o valor já criado se conserve como valor".

A coerência interna do raciocínio é inquestionável. Porque é precisamente então, conclui, que haverá soado a hora da revolução social, dado que as relações de produção capitalistas terão esgotado seu potencial de progresso para converter-se em um freio para o desenvolvimento das forças produtivas. Em outras palavras, o capitalismo terá se tornado supérfluo.

Se restar alguma dúvida sobre o ponto que mais me importa ressaltar, voltemos novamente a Marx: "O pilar fundamental da produção e da riqueza não é [agora] nem o trabalho imediato executado pelo 
homem nem o tempo que este trabalha, mas a apropriação da sua própria força produtiva geral, sua compreensão da natureza e seu domínio da mesma, graças à sua existência como corpo social; em poucas palavras, o desenvolvimento do indivíduo social".

Daí uma passagem decisiva, que o próprio autor enfatiza: "O roubo de tempo de trabalho alheio, sobre o qual repousa a riqueza atual, aparece como base miserável comparado com esse fundamento, recém-desenvolvido, criado pela própria grande indústria”.

Só que essas agudas observações sobre o presente e o futuro do capitalismo formuladas, vale lembrar, há mais de um século e meio - são as que dão margem à minha hipótese, pois conduzem, por sua vez, a uma dificuldade da maior importância que Marx não conseguiu superar nos termos de seu próprio paradigma teórico.

4.

Porque se impõe uma pergunta: ao chegar a anunciada hora da revolução social, quem serão seus agentes, se até lá a automatização terá reduzido sensivelmente as filas do proletariado industrial, isto é, dessa "classe trabalhadora oprimida e disciplinada" a que se referia Sweezy?

Apresso-me a complementar essa pergunta com duas observações. A primeira é que a mencionada ideia básica de que se ingressa num período revolucionário quando um modo de produção esgotou todas as suas possibilidades de desenvolvimento autoriza minha inferência sobre um avanço da automatização cada vez mais intenso e prolongado. A segunda, que isso não quer dizer que, nesse futuro que Marx vislum- brava, o trabalho manual industrial terá desaparecido por completo, mas é inegável que se contrapõe ao pré-requisito que ainda em 1875 continuava se fixando a uma "revolução social radical", isto é, que "o proletariado industrial constitua pelo menos uma parte considerável do povo" (Marx, 1976, p. 411). (Atualmente, é notório que nos principais países capitalistas o movimento operário nem sequer pode aspirar a converter-se por si mesmo em uma maioria eleitoral. Como anota Przeworski [1980, p. 39]: “Os socialistas têm que escolher entre um partido que seja homogêneo em sua apelação de classe, mas esteja sentenciado a derrotas eleitorais perpétuas, e um partido que lute pelo triunfo eleitoral às custas de diluir seu caráter de classe".)

Teriam finalmente motivo os anarquistas, com quem Marx e Engels estiveram brevemente associados nos anos 1840, mas cujas posições posteriormente não cansaram logo de criticar? De sua parte, os anarquistas os viam como seus inimigos por considerar que no fundo eram os ideólogos de um tipo de aristocracia do trabalho, enquanto eles se assumiam como os intérpretes legítimos da plebe, dos excluídos, dos pobres, que eram na realidade os chamados a liquidar a dominação em todas suas formas precisamente porque o desenvolvimento das forças produtivas os deixava inexoravelmente à margem. Assim, ao partido trabalhador organizado que Marx acreditava destinado a ser o protagonista de uma futura "ditadura revolucionária do proletariado" em transição ao comunismo, Mikhail Bakunin ou Peter Kropotkin opunham a insurgência espontânea dos debaixo e a criatividade de sua "paixão pela destruição". O terrorismo e a 
agitação, afirmavam, eram as formas mais eficazes de revelar a vulnerabilidade dos setores dominantes e, como proclamaria nesses anos Errico Malatesta, a ação direta constituía o modo por excelência de fazer propaganda através dos fatos.

Marx não apenas rechaçava o espírito individualista que alimentava essas posturas e advertia que Bakunin "não tinha ideia do que era uma revolução social", mas ainda, por sua vez e no outro extremo, em 1859 criticava também Ferdinand Lassalle, que havia sido seu amigo e que então - como fiel discípulo de Hegel - havia se aproximado de Bismarck, convencido de que era imprescindível a ação do Estado para proteger os fracos. (Enquanto liquidava os socialistas, Bismarck ditava a legislação social mais avançada da sua época e é normalmente considerado um precursor dos "Estados de bem-estar" posteriores à Segunda Guerra Mundial.)

Descartadas essas alternativas, parece-me mais que plausível imaginar que uma mente tão inquisidora como a de Marx percebeu o beco sem saída ao qual levavam suas próprias previsões sobre a automatização. Quem seriam "os coveiros da burguesia" dos quais falava $O$ Manifesto Comunista? ${ }^{8}$. Um reduzido contingente de supervisores e reguladores dos processos fabris, presumidamente bem-remunerados? Daí a inquietação de

8 Essa menção não é excêntrica. O Manifesto Comunista (1848) é uma das quatro obras escritas por ele que Marx sempre reivindicou e cujas reedições autorizou até o fim de seus dias. Além disso: "O capital e $O$ Manifesto Comunista aparecem [...] absolutamente articulados" (Aricó, 1971, p. XI). Mais recentemente, Burawoy (2000, p. 153) defendeu com força a ideia de uma reconstrução teórica do marxismo a partir de $O$ Manifesto Comunista. seus últimos anos, nos quais não conseguiu encontrar uma saída convincente para o seu dilema apesar de todas as suas tentativas. (Seu último esforço sério data de 1878 e o abandonou depois de sete páginas [Jones, 2016, p. 204]). Creio que é precisamente por isso que "até o final de sua vida [Marx] tinha uma dolorosa consciência de que os trabalhos que havia apresentado ou estava a ponto de apresentar em público eram tão somente fragmentos" (Nicolaus, 1971, pp. XXXVIII e XL ). Com o agravante de que Marx sabia que suas reflexões e incertezas de maturidade "eram demasiado sutis para seus seguidores" (Lichteim, 1970, p. 85) ${ }^{9}$.

\section{5.}

Ele pensa, por exemplo, que existem tendências morosas da derrocada, como a conquista de novos mercados, o pagamento de "salários excedentes" aos trabalhadores ou os aumentos de salário real por causa das lutas operárias e do barateamento dos bens de consumo devido à maior produtividade. E isso o induz a perguntar-se se por acaso a transição ao socialismo não poderia acontecer finalmente de maneira bastante gradual, como aconteceu antes com o surgimento do capitalismo ${ }^{10}$. Em 1844 , ele havia postulado que o lugar da educação política da classe trabalhadora era a fábrica, uma vez que "não em vão o

9 Acrescento que esse autor faz abundante uso dos Grundrisse.

10 Este é um dos eixos principais do livro de Gareth Stedman Jones (2016). Em 1872, em um conhecido discurso pronunciado em Amsterdã, Marx aceitou que em certos países, como Estados Unidos, Inglaterra e talvez Holanda, seria possível chegar ao socialismo por meios pacíficos (ver Tucker, 1978, p. 523). 


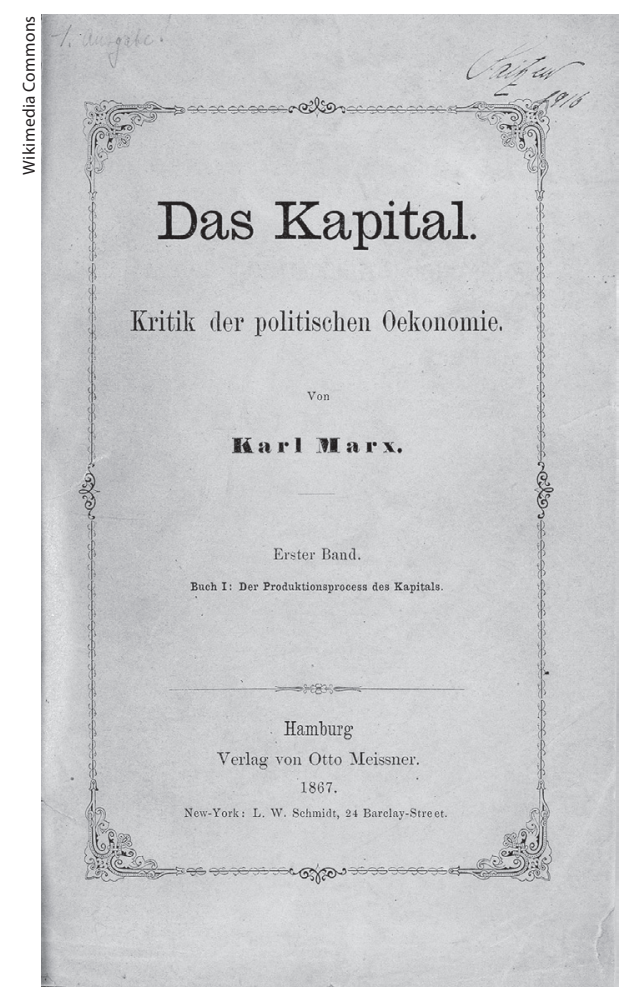

Capa da primeira edição (1867) de O capital

proletariado passa pela escola do trabalho, dura mas forjadora de caráter" (Marx \& Engels, 1967, p. 102). Em 1866, aponta os sindicatos como potenciais "escolas de socialismo", que irão se constituindo em "centros de organização da classe trabalhadora, tal como as municipalidades e as comunas medievais foram da classe média" (Marx, 1976). Em todo caso, o protagonista da mudança segue sendo o proletariado industrial, portador dessa racionalidade crescente que lhe atribuí e que critiquei em outro lugar (ver Nun, 2015, pp. 57-100). Mas, repito, e se o avanço do capitalismo e a modernização das forças produtivas vão reduzindo cada vez mais seu volume e sua homogeneidade?

Importa-me destacar que, no entanto, sua correspondência revela que não compartilhou essas dúvidas com Engels, que manteve decididamente sua fé revolucionária e escreveu à sua luz o muito influente Anti-Dühring (1878) e editou e corrigiu também com esse critério os volumes II e III de $O$ capital. Tanto é assim que, ainda em 1880, Engels interpretava que o progressivo choque entre os oligopólios em ascensão e os sindicatos e partidos socialistas anunciava o rápido final do capitalismo, "quando de fato constituía o amanhecer de um capitalismo novo e robusto - o capitalismo organizado" (Burawoy, 2000, p. 159) ${ }^{11}$. Pelo exposto até aqui, é improvável que esse desenlace tivesse surpreendido Marx demasiadamente (cf. Lichteim, 1970, p. 105).

Claro que, ao mesmo tempo, este expressa sua admiração pela coragem dos terroristas russos que, em 1881, assassinaram o czar Alexandre II, apelando para um "método de ação inevitável" nesse contexto. Porém, ilude-se com uma guerra europeia contra o czarismo, "baluarte da reação", que poderia reavivar as energias adormecidas do conjunto das classes trabalhadoras. Por outro lado, dedica-se a estudar as comunas medievais que precederam o capitalismo para avaliar a possibilidade de que sociedades como a russa se achassem em condições de passar diretamente ao socialismo, sem uma etapa capitalista intermediária. Mas são pontuações conjunturais que não estão à altura das proposições que citei antes, e Marx - cuja permanente insatisfação com

11 É importante destacar que, como aponta Shenk seguindo Stedman Jones, "foi a versão de Engels do marxismo que ofereceu sua base intelectual à geração seguinte de teóricos marxistas e projetou sua sombra sobre o século XX" (Shenk, 2017, p. 19). 
os vácuos teóricos de seus trabalhos é bem conhecida - não pode tê-las ignorado.

Ocorre que, tal como as formula, suas teses sobre a derrocada capitalista e a luta de classes acabam resultando incompatíveis e esse capítulo 52 de $O$ capital, que deixou truncado e nunca completou, se torna o melhor testemunho disso. Como conciliar a luta de classes tal como a vinha planejando desde 1848 com uma automatização crescente que o levava a intuir que a concentração $e$ a centralização do capital estariam acompanhadas pelo estreitamento, a fragmentação e a divisão dos setores proletários? Para poder fazê-lo, teria que desconectar sua epistemologia do que provou ser sua utopia social. E esse é um passo que nunca deu.

6.

É sabido que, no primeiro volume de $O$ capital, Marx toma o caso da Inglaterra como base de sua reflexão teórica porque "só aqui o modo capitalista de produção se desenvolveu de maneira plena" (Marx, 1975, tomo I, vol. 3, p. 808).

Historicamente, esse desenvolvimento corresponde à fase competitiva do capitalismo, protagonizada por empresas intensivas em mão de obra e sujeitas a ciclos decenais "de animação média, prosperidade, sobreprodução, crises e estancamento" (Marx, 1975, tomo I, vol. 2, p. 551).

Trata-se de uma época em que as máquinas tendem a uma progressiva desqualificação profissional do operário, destruindo a hierarquia de trabalhadores especializados característica da manufatura, e por isso Marx dá por suposto o aumento da homogeneidade do proletariado nessa etapa, o que facilita que um trabalhador seja substituído por outro.

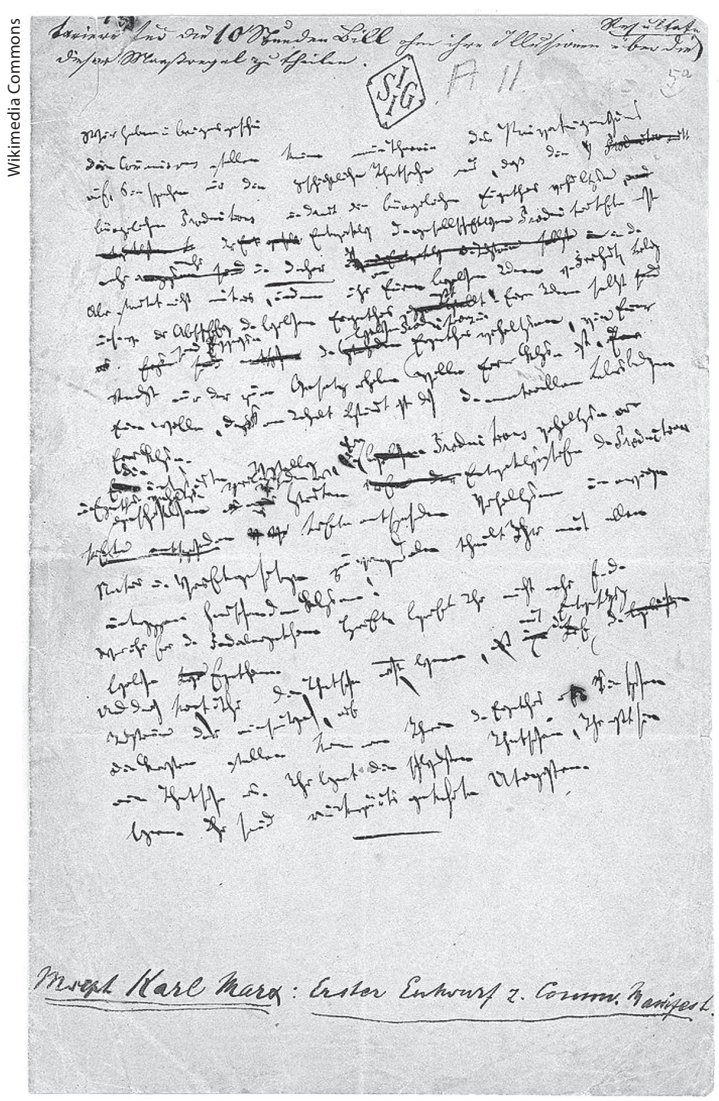

Página do primeiro rascunho de O Manifesto Comunista

Isso o leva a organizar sua análise do mercado de trabalho industrial em torno da "modalidade flutuante" da superpopulação relativa e gera um efeito duplo: por um lado, identifica os conceitos de superpopulação relativa e de exército industrial de reserva; e, por outro, supõe que esse vaivém entre a ocupação e a desocupação seja uma experiência comum para a maioria dos operários e não gere, portanto, nenhum problema político específico.

Meus trabalhos sobre os excedentes não funcionais da superpopulação relativa - que denominei massa marginal - tiveram como ponto de partida uma crítica ao primeiro desses efeitos, e a eles me remeto. Por um lado, a hipótese que quero expor se vincu- 
la à segunda consequência mencionada e, como disse anteriormente, contribuiu direta ou indiretamente para a apresentação de alguns de meus temas de estudo ${ }^{12}$. Deter-me-ei brevemente aqui em um deles, o conceito de regime social de acumulação, pois se conecta, por sua vez, com meu tratamento de assuntos tão diversos como as transições para a democracia, os significados do peronismo ou as relações entre a teoria, a ideologia e o senso comum.

\section{7.}

Como escrevi em outro lugar, a origem do conceito é uma crítica a essa ideia da economia como um domínio autônomo e autossuficiente, que Adam Smith apresentou pela primeira vez em 1776, em sua crítica à doutrina mercantilista (Nun, 2001) ${ }^{13}$. A partir de tal perspectiva, em um mercado de livre-concorrência os comportamentos dos atores econômicos tendem a agregar-se em uma totalidade racional e sustentável, sem necessidade de nenhuma intervenção política. Essa posição dos economistas clássicos foi parcialmente aceita por Marx, que questionava a racionalidade da economia capitalista, mas não a existência de uma lógica que lhe era inerente. Essa lógica a tornaria capaz de regular a si mesma, graças ao próprio "efeito purificador" das crises cíclicas (cf. Block, 1986, p. 180).

Em contraste, já em 1903 Durkheim e Fauçonnet fustigavam os economistas

12 Ver, por exemplo, Nun (1989).

13 Nos parágrafos seguintes baseio-me parcialmente neste texto. clássicos por terem criado "um mundo econômico que não existe, um Guterwelt ["mundo bom"], um mundo isolado, que é sempre idêntico a si mesmo e no qual os conflitos entre forças puramente individuais são solucionados de acordo com leis econômicas imutáveis". E concluíam que: "Na realidade, é no interior de coletividades que são bastante diferentes umas das outras onde os indivíduos tratam de enriquecer; e tanto a natureza como o êxito desses esforços mudam junto com a natureza da coletividade na qual aparecem" (Durkheim \& Fauçonnet, 1903, p. 487) ${ }^{14}$.

Mas seria Karl Polanyi que, 40 anos mais tarde, estenderia e aprofundaria essa crítica, explicando que a ação do Estado é sempre indispensável para que impere a lei e a mera posse se converta, assim, em propriedade, como que para organizar e regular os mercados, os contratos, os sistemas de moeda e crédito, a oferta de mão de obra, as relações trabalhistas, os serviços de infraestrutura, o comércio exterior, as pautas de crescimento urbano etc. Ou seja, que, contra qualquer determinismo econômico, as políticas estatais são constitutivas das economias capitalistas, que não poderiam operar em sua ausência.

Este é o pressuposto da noção de regime social de acumulação (RSA), que designa o conjunto complexo das instituições e das práticas que incidem no processo de acumulação de capital, entendendo este último como uma atividade

14 Comparar com O Manifesto Comunista: “O trabalho industrial moderno, o moderno jugo do capital, que é o mesmo na Inglaterra e na França, nos Estados Unidos e na Alemanha, priva o proletariado de todo carácter nacional" (Marx \& Engels, 1973, vol. 1, p. 118). 
microeconômica de geração de lucro e de tomada de decisões de investimento.

Por isso a visão de Marx da luta de classes leva ao essencialismo quando se remete a uma suposta autonomia da economia, risco do qual só escapou claramente em seus trabalhos históricos, mas não em $O$ Manifesto Comunista. Nesse sentido, é notável cotejar a distinta leitura que ele e Gramsci fizeram de um parágrafo famoso de Hegel sobre a estrutura da sociedade civil: Marx ateve-se somente ao primeiro de seus componentes - o sistema de necessidades - e o tornou sinônimo de economia, enquanto Gramsci concentrou sua atenção nos outros elementos - a administração de justiça e a polícia e as corporações (Hegel, 1967, p. 126).

\section{8.}

A partir da posição que adoto - decididamente mais próxima de Gramsci que de Marx -, o primeiro momento da análise do processo de formação das classes sociais não deve se concentrar na economia, mas no RSA, isto é, em uma estrutura institucional complexa, produto de uma história particular que dá saliência a determinados atores e práticas, que estabelece condições de recepção mais favoráveis para certos discursos que para outros e em cujo contexto começam a cobrar sentido, por isso mesmo, identidades, oposições e lutas que as redes de relações sociais restantes podem inibir ou potencializar.

Em outras palavras, as classes emergem e se desenvolvem ou não como tais "conforme homens e mulheres vivem suas relações produtivas e experimentam suas posições dentro do conjunto das relações sociais, com sua cultura e suas expectativas herdadas e de acordo a como interpretem e manejem essas experiências" (Thompson, 1978, p. 149). Por isso, enquanto as narrações economicistas privilegiam as grandes histórias contínuas das classes sociais, uma leitura em termos de RSAs acentua as descontinuidades, as mudanças que ocorrem na situação dos atores e as imagens prevalecentes que dão conteúdo a suas reivindicações e, de acordo com as circunstâncias, conferem uma maior ou menor centralidade às práticas concretas de grupos específicos.

Para dar um passo mais, a sociedade civil é uma categoria que designa um campo de interações sociais "composto principalmente pela esfera íntima (especialmente a família), a esfera das associações (especialmente as associações voluntárias), os movimentos sociais e as formas de comunicação pública" (Arato \& Cohen, 1992, p. IX ). Segue-se então que num sistema capitalista o RSA atua como mediador entre a sociedade civil e o mercado, bem como o que chamo de regime político de governo (RPG) atua como mediador entre a sociedade civil e o Estado, ao mesmo tempo em que um e outro se articulam de modos mais ou menos concordantes ou conflitivos (Nun, 2015, p. 304).

\section{9.}

Para finalizar, e se minha hipótese é correta, o problema que Marx enfrentou deve-se tanto a essa leitura reducionista de Hegel que assinalei como a que não pôde cumprir seu longo propósito de elaborar uma teoria do Estado.

Segundo se depreende do que foi dito até agora, nenhuma análise das estruturas pode prever qual será o comportamento 
dos atores, exceto se trabalharmos com uma ideia de transparência, que, como já indiquei, não foi nada alheia ao racionalismo de Marx. Para recorrer a termos que se tornaram clássicos, uma coisa é a integração das partes de um sistema (aqui, as forças produtivas e as relações de produção) e outra, os níveis de integração social dos agentes (burgueses e proletários) (ver Lockwood, 1964). Ou seja, que a teoria da derrocada capitalista tal como aparece exposta nos Grundrisse apresenta duas deficiências: uma se refere à evolução quantitativa e qualitativa da classe operária, problema que o próprio autor vislumbrou; a outra remete a um tema que observou só de passagem.

Refiro-me ao fato de que os interesses e a consciência de classe não vêm dados, mas são produzidos histórica e socialmen- te, de maneira que em uma determinada conjuntura se abrem sempre vários caminhos alternativos, por mais que o leque de opções possíveis seja delimitado pelos compromissos ideológicos, pelos limites organizativos ou pelas relações de força. É certo que, no discurso de Amsterdã de 1872 que citei páginas atrás, Marx nega ter afirmado que os trabalhadores chegariam ao poder pelas mesmas vias em todas as partes e aceita que tenha que levar em consideração "os costumes e as instituições dos diversos países"15. Mas é uma menção ocasional que não chegou a incorporar ao seu corpo teórico.

Em qualquer caso e no final deste percurso, espero que o leitor compartilhe comigo uma conclusão: às vezes, as dúvidas e as hesitações de um gênio podem nos ensinar tanto ou mais que suas certezas. 


\section{REFERÊNCIAS}

ARATO, A.; COHEN, J. L. Civil society and political theory. Cambridge, The MIT Press, 1992. ARICÓ, J. "Presentación", in K. Marx, O capital, Livro I, Capítulo VI (inédito). Trad. Pedro Scaron. Buenos Aires, Ed. Siglo XXI, 1971.

BLOCK, F. "Political choice and the multiple 'logics' of capital". Theory and Society, vol. 15/1-2. Dordrecht, 1986.

BURAWOY, M. "Marxism after communism". Theory and Society, vol. 29/2. California, 2000. DURKHEIM, E.; FAUÇONNET, P. "Sociologie et sciences sociales". Révue Philosophique, n. 55. Paris, 1903.

GODELIER, M. Rationalité et irrationalité en économie. Paris, Ed. Maspero,1966.

HART, M. The 100: a ranking of the most influential persons in history. New York, Citadel, 2000. HEGEL, G. W. F. Philosophy of right. Trad. T. M. Knox. Londres, Oxford University Press, 1967. JONES, G. S. Karl Marx: greatness and illusion. Londres, Penguin, 2016.

LICHTEIM, G. A short history of socialism. Londres, Weidenfeld and Nicholson, 1970. LOCKWOOD, D. "Social integration and system integration", in G. K. Zollschan; H. W. Hirsch (eds.). Explorations in social change. Boston, Houghton Mifflin, 1964. MARX, K. "From comments on Bakunin's book Statehood and Anarchy", in K. Marx; F. Engels. Selected works in three volumes, vol. 2. Moscou, Progress Publishers, 1976. MARX, K. "Instructions for the Delegates of the Provisional General Council", in K. Marx; F. Engels. Selected works in three volumes, vol. 2. Moscou, Progress Publishers, 1976, pp. 82-3.

MARX, K. El capital. Trad. Pedro Scaron. Buenos Aires, Siglo XXI, 1975.

MARX, K. Elementos fundamentales para la crítica de la economía política (borrador) 1857-1858, vol. II. Trad. Pedro Scaron. Buenos Aires, Siglo XXI, 1972.

MARX, K. O capital, Livro I, Capítulo VI (inédito). Trad. Pedro Scaron. Buenos Aires, Siglo $\mathrm{XXI}, 1971$.

MARX, K.; ENGELS, F. La sagrada familia. Trad. W. Roces. México, Grijalbo,1967. NICOLAUS, M. "El Marx desconocido", in K. Marx. Elementos fundamentales para la crítica de la economía política (borrador) 1857-1858, vol. I. Trad. Pedro Scaron. Buenos Aires, Siglo XXI, 1971.

NUN, J. "Régimen social de acumulación", in T. S. Di Tella et al. Diccionario de ciencias sociales y políticas. Buenos Aires, Emecé, 2001, pp. 598-600.

NUN, J. El sentido común y la política. Buenos Aires, Fondo de Cultura Económica, 2015. NUN, J. La rebelión del coro. Buenos Aires, Nueva Visión, 1989.

NUN, J. Marginalidad y exclusión social. Buenos Aires, Fondo de Cultura Económica, 2001. PRZEWORSKI, A. Social democracy and a historical phenomenon. Londres, New Left Review, 1980.

SHENK, T. "Find the method". London Review of Books. Londres, 29/6/2017.

SWEEZY, P. M. Teoría del desarrollo capitalista. Trad. Hernán Laborde. México, Fondo de Cultura Económica, 1945.

THOMPSON, E. P. "Eighteenth century English society: class struggle without class?". Social History, 3:2. Londres, 1978.

TUCKER, R. C. (ed.). The Marx - Engels reader. New York, W. W. Norton, 1978. WOLFF, J. "Readers of the world unite". The Time Literary Supplement, 30/10/2018. 